\title{
The mediating effect of self-efficacy in the relationship between communication skills and practices of preventing infectious diseases among daycare center teachers in South Korea
}

\author{
Jieun Shin ${ }^{1}$, Sun Young You ${ }^{2}$ \\ ${ }^{1}$ Assistant Professor, Liberal Arts, Woosuk University, Wanju; ${ }^{2}$ Assistant Professor, College of Nursing, Sungshin Women's University, Seoul, Korea
}

Purpose: This study investigated the practices of preventing infectious diseases by daycare center teachers. The focus was on the mediating effects of self-efficacy in the relationship between communication skills and practices of preventing infectious diseases. Methods: This study used a descriptive correlational design. The participants were 164 daycare center teachers. Hierarchical regression was used to test the mediating effect of self-efficacy in the relationship between communication skills and practices of preventing infectious diseases. Data were analyzed using the independent $t$-test, one-way analysis of variance, Pearson correlation coefficients, and hierarchical regression. The mediation effect was analyzed using an SPSS Macro program, PROCESS. Results: Significant relationships were found between communication skills and practices of preventing infectious diseases $(\beta=.19, p<.001)$, self-efficacy and practices of preventing infectious diseases $(\beta=.59, p<.001)$, and communication skills and self-efficacy $(\beta=.27$, $p<.001)$. Self-efficacy had a significant mediating effect $(\beta=.17,95 \%$ confidence interval $=0.07-0.29)$ on practices of preventing infectious diseases. Conclusion: In order to improve practices of preventing infectious diseases among daycare teachers, it is necessary to develop and apply interventions and methods that can increase effective communication skills and self-efficacy.

Key words: Child day care centers; Communication; Self-efficacy; Infection; Prevention

\section{Corresponding author Sun Young You \\ https://orcid.org/0000-0003-2763-1403}

College of Nursing, Sungshin Women's University,

55 Dobong-ro, 76 ga-gil, Gangbuk-gu, Seoul 01133, Korea

TEL +82-2-920-2715 FAX +82-504-181-6210

E-MAIL sy-you@sungshin.ac.kr

*This study was supported by the research fund of Sungshin Women's University of Korea in 2020

Received Dec 8, 2020 Revised Dec 25, 2020 Accepted Jan 5, 2021 (a) This is an Open Access article distributed under the terms of the Creative Commons Attribution NonCommercial License (http://creativecommons.org/licenses/by-nc/4.0/) which permits unrestricted noncommercial use, distribution, and reproduction in any medium, provided the original work is properly cited.

\section{INTRODUCTION}

\section{Background}

The transition towards the nuclear family and the increase in women's economic activities are causing challenges in raising children compared to the past [1,2]. In South Korea (hereafter, Korea), various childcare policies are being implemented to reduce the burden of parenting at home and to increase the fertility rate [3]. Starting in 2013, free education for children aged 0-5 years was introduced [4], and the number of childcare facilities increased from only 1,919 in 1990 to 37,371 in 2019 [5]. In recent years, interest in the quality of child safety and health management is increasing, instead of a focus on increasing the quantity of childcare facilities and simple child-rearing [6,7].

Children interact in groups at daycare centers and are at the oral stage of development [6]. In addition, children are more likely to contract various infectious diseases because their immune systems are not fully developed compared to adults [8]. For this reason, infectious diseases continue to occur at daycare centers, affecting children's health and well-being [9]. Of particular note, coronavirus disease 2019 (COVID-19), which 
emerged in China in 2019, has caused a global pandemic [10]. Daycare centers are not a safe place in terms of COVID-19 infection, and an increasing number of teachers and students are infected with COVID-19 [8,11].

According to Korea's Child Care Act, the ultimate goal of health management for infants and toddlers is to protect the mind and body of infants and to educate them soundly to nurture them as members of a healthy society, as well as to promote family welfare by ensuring that parents' economic and social activities are smoothly performed [12]. Nurses were assigned to daycare centers that care for more than 100 infants and toddlers to take care of the health and safety of children [12]. However, in reality, nurses are rarely assigned to daycare centers, and daycare center teachers play a comparable role regarding the health and safety of children. Infants and toddlers using daycare centers spend most of their time with childcare teachers in childcare facilities [12,13]. At daycare centers, teachers are in charge of not only caring for infants and children, as well as the management and operation of childcare facilities, but also health care and counseling with guardians [13]. In the current situation, childcare teachers are in an important position to detect health problems early by maintaining and promoting the health of infants and young children, preventing diseases, and seeking help from guardians or experts [14].

In the effective management of infectious diseases of infants and toddlers at childcare centers, the practices of preventing infectious diseases before they occur is emphasized rather than coping with infections after they occur $[9,13]$. An individual's communication skills influence the achievement of effective goals within an organization [15]. In Jeong and Kim's study [16], communication skills were found to improve problemsolving abilities among daycare center teachers. Above all, daycare center teachers, who are non-medical professionals in charge of preventing and managing children's infectious diseases at daycare centers, require effective communication skills to practices infectious disease prevention $[13,14]$. Daycare teachers are also required to communicate effectively about infectious diseases in the COVID-19 pandemic situation [14]. Effective communication skills of daycare teachers are thought to help prevent infectious diseases, but research on this issue is insufficient. Self-efficacy is defined as an individual's confidence in being able to take adaptive actions and to manage the many unpredictable environmental demands that he or she faces [17]. In the prevention of infectious diseases, self-efficacy refers to an individual's skills to evaluate his or her degree of knowledge and willingness for behavior change [18]. In the study of Yang and Kwon [19], the self-efficacy of daycare center teachers increased practices of preventing infectious diseases.
A previous study found that communication skills between daycare center teachers and parents influenced teachers' self-efficacy [20]. However, research on the relationship between the communication skills of daycare center teachers and self-efficacy for preventing infectious diseases is insufficient. In order to practice health promotion behaviors for infectious disease prevention, it is necessary to understand the relationship between the child-care teachers' communication skills (as a personal characteristic) and self-efficacy (as a behavior-related characteristic). Therefore, this study aimed to determine the degree of communication skills, self-efficacy, and practices of preventing infectious diseases among daycare teachers. In addition, the purpose of this study was to determine how communication skills affected practices of preventing infectious disease, and how self-efficacy mediated that relationship. Through this, we intended to provide basic data for the development of strategies to increase practices of preventing infectious diseases by daycare teachers.

The purpose of this study was to verify the mediating effect of self-efficacy in the relationship between communication skills and practices of preventing infectious diseases among daycare center teachers. The specific purposes of this study were as follows. First, differences in communication skills, self-efficacy, and practices of preventing infectious diseases among daycare teachers according to teachers' general characteristics were investigated. Second, the relationships between communication skills, self-efficacy, and practices of preventing infectious diseases among daycare teachers were investigated. Third, the mediating effect of self-efficacy in the relationship of communication skills with practices of preventing infectious diseases among daycare teachers was investigated.

\section{METHODS}

\section{Study Design}

This descriptive correlation study was conducted to determine the mediating effect of self-efficacy in the relationship between communication skills and infectious disease prevention practices among daycare center teachers.

\section{Measures}

\section{1) Communication skills competence}

Communication skills competence is the ability to communicate and understand opinions through interactions with others [21], and in this study, it referred to the ability of daycare center teachers to effectively interact with others by recognizing and utilizing appropriate means of communication in rela- 
tionships with others. The questionnaire of Kim et al. [15], which modified and supplemented the communication ability measurement tool developed by Heo [22], was used. This tool is presented on a 5-point Likert scale with a total of 15 questions, and each question is to be answered on a 5-point scale from "not at all (1 point)" to "very much so (5 points)." A higher score indicates higher communication skills. When the tool was developed, the reliability was indicated by a Cronbach's $\alpha$ of .89 [15]. The Cronbach's $\alpha$ of the tool was .86 in this study.

\section{2) Self-efficacy in prevention of infectious diseases}

Self-efficacy is the belief that an individual can perform a job successfully, and an individual's belief in one's confidence and confidence in one's ability to organize and perform the actions necessary to perform a particular action in a particular situation [17]. Kim and Park [18] developed a tool to measure self-efficacy in prevention of infectious diseases among daycare teachers, which consists of a total of 15 questions on a 4-point scale from "not at all (1 point)" to "Strongly agree (4 points)" [18]. A higher score indicates higher self-efficacy. When the tool was developed, the reliability was indicated by a Cronbach's $\alpha$ of .90 [18]. The tool's Cronbach's $\alpha$ was .87 in this study.

\section{3) Practices of preventing infectious diseases}

Practices of preventing infectious diseases are actions that daycare center teachers must carry out to prevent children from contracting infectious diseases [18]. This study used a tool that was developed by Kim and Park in 2014 [18]. The degree of practices of preventing infectious diseases was assessed using 15 questions, each of which was answered on a 4-point scale from "not at all (1 point)" to "very much so (4 points)." A higher score indicates a higher level of practice of preventing infectious disease. This tool consists of three subcategories: "sanitary management" for preventing infectious diseases, "observing and dealing with infectious diseases," and "environmental management." The reliability of this tool at the time of development was shown by a Cronbach's $\alpha$ of .86 [18]. The Cronbach's $\alpha$ of the tool was .86 in this study.

\section{Data Collection}

The data collection for this study was conducted for 4 weeks (from July 11 to August 1, 2020) after Institutional Review Board (IRB) approval. Due to the spread of COVID-19, visits to daycare centers by outsiders are limited, so the research director distributed descriptive questionnaires to teachers, colleagues, and directors, most of whom the research director knew. For data collection, the researcher called childcare facilities located in A city, $\mathrm{K}$ city, and $\mathrm{S}$ city to explain the pur- pose and method of the study and asked for consent to participate in the study. Data were collected from questionnaires administered to teachers at six childcare facilities that agreed to participate in the study. The survey was conducted in the director's office or the counseling room, where the childcare teacher could comfortably participate in the study, and the survey took about 20 to 30 minutes.

\section{Participants}

The participants in this study were teachers working at daycare centers. The basis for the calculation of the subject size for this study was calculated as a minimum sample size of 134 subjects with an effect size of .30, a significance level of .05, and a power of .95 using $t G^{*}$ Power version 3.1.2. The criteria for selecting participants for the study were as follows. First, adults over the age of 20 years and under the age of 65 years; second, teachers in charge of childcare at daycare centers; third, childcare teachers who agreed to participate in this study; childcare teachers who could understand and respond to the content of the questionnaire. Questionnaires were administered to 175 people considering the possibility of incomplete responses; after the exclusion of nine questionnaires with insufficient responses, surveys from 164 respondents were surveyed.

\section{Data Analysis}

The data were analyzed using SPSS version 25.0 for Windows (IBM Corp., Armonk, NY, USA). The frequency and percentage $(\%)$ of the variables for subjects' general characteristics were presented. In addition, differences in communication skills, self-efficacy, and practices of preventing infectious diseases according to general characteristics were compared by the independent t-test and one-way analysis of variance. The relationships between communication skills, self-efficacy, and practices of preventing infectious diseases were analyzed using Pearson correlation coefficients. To investigate the mediating effect of self-efficacy on the relationship between communication skills and practices of preventing infectious diseases, the hierarchical regression technique presented by Baron and Kenny [23] was used, and Hayes' [24] SPSS Macro program, PROCESS, was used for the analysis. Of the various PROCESS analysis methods, model 4 was used in this study, with 5,000 rounds for bootstrapping, The mediating effect was tested at a $95 \%$ confidence interval.

\section{Ethical Considerations}

This study was conducted after deliberation by the Research 
Ethics Committee of Sungshin Women's University to which the researcher is affiliated (IRB No. SSWUIRB-2020-020). Participants who decided to complete the questionnaire received an explanation of the purpose of the study and the research process. In this study, subjects who provided voluntary consent in oral and written form completed the questionnaire. It was explained before the start of data collection that if it was uncomfortable to answer the questionnaire, participants had the right not to answer the questions, and that participation in the study could be withdrawn. The completed questionnaires were kept so that they were not exposed to others, and personal information was managed by assigning a unique number to each participant. The researcher explained to the survey participants that the researcher would directly discard the data collected at the end of the study. It was explained that the research report would be prepared without revealing the personal information of the participants, and the research was conducted with the participants who agreed. Records regarding consent to participate in the study were kept separately.

\section{RESULTS}

\section{General Characteristics of Participants}

The demographic and sociological characteristics of the daycare teachers consisted of eight categories: age, marital status, type of facility, career experience, size of facility, sources of information on infection, experience of education (infection prevention), and perceived requirements for infection prevention. All 164 participants in the study were women. The distribution of age was as follows: $20-29$ years, $7.3 \%$ (12 persons); $30-39$ years, $28.7 \%$ ( 47 persons); $40-49$ years, $51.8 \%$ (85 persons); $50-59$ years, $12.2 \%$ (20 persons). Regarding marital status, $74.4 \%$ (122 persons) of the participants were married and $25.6 \%$ (42 persons) were unmarried. Most of the respondents worked at private childcare facilities $(53.1 \%$; 85 persons), followed by family education facilities $(25.6 \% ; 41$ persons), government support childcare facilities $(10.0 \% ; 16$ persons), and others (11.3\%; 18 persons). Most of the respondents $(66.5 \%$; 109 persons) had between 5 and 10 years of experience, $17.7 \%$ ( 29 persons) had more than 10 years of experience, and $15.8 \%$ ( 26 persons) had less than 5 years of experience. The majority of the respondents $(59.8 \%$; 98 persons) worked at childcare centers with 50 or fewer children, $26.2 \%$ (43 persons) worked at centers with 51-100 children, and $14.0 \%$ (23 persons) worked at centers with 101 or more children. The most common source of information on infection was continuing education ( $43.3 \%$; 71 persons), followed by infection prevention guidelines $(26.2 \%$; 43 persons), the internet $(22.0 \%$; 36 persons), and others $(8.5 \%$; 14 persons). Over three-quarters of respondents $(76.2 \%$; 125 persons) reported having received education on this topic. The most necessary item for infection prevention was improvement of awareness of infection prevention by teachers and parents $(62.2 \%$; 102 persons), followed by regular infection prevention education for the participants (15.8\%; 26 persons), others (10.4\%; 17 persons), the presence of a resident nurse $(6.7 \%$; 11 persons), and regular visit training by experts $(4.9 \% ; 8$ persons).

\section{Differences in Communication Skills, Self-efficacy, and Practices of Preventing Infectious Diseases by General Characteristics of Participants}

Differences in communication skills, self-efficacy, and practices of preventing infectious diseases according to the general characteristics of the study participants were analyzed. No statistically significant difference in communication skills was found according to general characteristics.

There was a statistically significant difference in the sense of self-efficacy according to the source of infection prevention information ( $\mathrm{F}=3.05, p=.030)$ and whether participants had received education on infection prevention $(\mathrm{t}=3.11, p=.002)$. Similarly, statistically significant differences in practices of preventing infectious diseases were found according to the source of infection prevention information ( $\mathrm{F}=2.91, p=.036)$ and whether participants had received information on this issue $(\mathrm{t}=3.19, p=.002)($ Table 1$)$.

\section{Correlations among Communication Skills, Self-effi- cacy, and Practices of Preventing Infectious Diseases}

Practices of preventing infectious diseases were significantly positively correlated with communication skills $(\mathrm{r}=.35$, $p<.001)$ and self-efficacy $(\mathrm{r}=.65, p<.001)$. Communication skills were also significantly positively correlated with selfefficacy $(\mathrm{r}=.27, p<.001)$ (Table 2).

\section{Mediating Effect of Self-efficacy in the Relationships between Communication Skills and Practices of Pre- venting Infectious Diseases}

We performed a three-step regression process [20]. Prior to the analysis, the absence of multicollinearity was confirmed, as tolerance was above the cutoff of 0.1 (at 0.9-1.0) and the variance inflation factors were below 10 (at 1.0-1.1). The normality of the error term was assessed using the Shapiro-Wilk test, and normality was confirmed with a p-value of larger than .050 (.056-.273) [25]. Further, the independence of residuals was confirmed with a d-value of 1.6-2.1 in the Durbin- Watson test, thereby confirming the absence of autocorrelation. 
Table 1. Differences in the Study Variables by General Characteristics of Participants $(N=164)$

\begin{tabular}{|c|c|c|c|c|c|c|c|c|}
\hline \multirow[t]{2}{*}{ Characteristic } & \multirow[t]{2}{*}{ Variable item } & \multirow[t]{2}{*}{$\mathrm{n}(\%)$} & \multicolumn{2}{|c|}{$\begin{array}{l}\text { Communication } \\
\text { skills }\end{array}$} & \multicolumn{2}{|c|}{ Self-efficacy } & \multicolumn{2}{|c|}{ PPID } \\
\hline & & & $\mathrm{M} \pm \mathrm{SD}$ & t or $\mathrm{F}(p)$ & $\mathrm{M} \pm \mathrm{SD}$ & t or $\mathrm{F}(p)$ & $\mathrm{M} \pm \mathrm{SD}$ & t or $\mathrm{F}(p)$ \\
\hline \multirow[t]{4}{*}{ Age (year) } & $20-29$ & $12(7.3)$ & $3.99 \pm 0.47$ & \multirow{4}{*}{$\begin{array}{l}1.41 \\
(.242)\end{array}$} & $3.33 \pm 0.46$ & \multirow{4}{*}{$\begin{array}{l}1.28 \\
(.282)\end{array}$} & $3.41 \pm 0.43$ & \multirow{4}{*}{$\begin{array}{c}0.73 \\
(.533)\end{array}$} \\
\hline & $30-39$ & $47(28.7)$ & $4.08 \pm 0.37$ & & $3.20 \pm 0.40$ & & $3.33 \pm 0.33$ & \\
\hline & $40-49$ & $85(51.8)$ & $3.99 \pm 0.35$ & & $3.21 \pm 0.41$ & & $3.26 \pm 0.42$ & \\
\hline & $50-59$ & $20(12.2)$ & $3.89 \pm 0.32$ & & $3.39 \pm 0.41$ & & $3.33 \pm 0.4$ & \\
\hline \multirow[t]{2}{*}{ Marital status } & Married & $122(74.4)$ & $3.99 \pm 0.34$ & \multirow{2}{*}{$\begin{array}{l}0.66 \\
(.420)\end{array}$} & $3.23 \pm 0.42$ & \multirow{2}{*}{$\begin{array}{c}0.10 \\
(.748)\end{array}$} & $3.31 \pm 0.39$ & \multirow{2}{*}{$\begin{array}{l}0.19 \\
(.665)\end{array}$} \\
\hline & Unmarried & $42(25.6)$ & $4.05 \pm 0.42$ & & $3.26 \pm 0.39$ & & $3.28 \pm 0.39$ & \\
\hline \multirow[t]{4}{*}{ Type of facility* } & Private childcare facility & $85(53.1)$ & $4.01 \pm 0.38$ & \multirow{4}{*}{$\begin{array}{l}0.41 \\
(.744)\end{array}$} & $3.22 \pm 0.41$ & \multirow{4}{*}{$\begin{array}{l}0.43 \\
(.731)\end{array}$} & $3.31 \pm 0.39$ & \multirow{4}{*}{$\begin{array}{l}0.90 \\
(.441)\end{array}$} \\
\hline & Government support & $16(10.0)$ & $4.07 \pm 0.38$ & & $3.23 \pm 0.47$ & & $3.28 \pm 0.37$ & \\
\hline & childcare facility & $41(25.6)$ & $3.98 \pm 0.35$ & & $3.30 \pm 0.45$ & & $3.34 \pm 0.39$ & \\
\hline & $\begin{array}{l}\text { Family education facility } \\
\text { Others }\end{array}$ & $18(11.3)$ & $3.95 \pm 0.28$ & & $3.18 \pm 0.33$ & & $3.16 \pm 0.48$ & \\
\hline \multirow{3}{*}{$\begin{array}{l}\text { Career experience } \\
\text { (year) }\end{array}$} & & $26(15.8)$ & $3.94 \pm 0.28$ & \multirow{3}{*}{$\begin{array}{l}0.96 \\
(.386)\end{array}$} & $3.31 \pm 0.36$ & \multirow{3}{*}{$\begin{array}{l}1.30 \\
(.275)\end{array}$} & $3.37 \pm 0.36$ & \multirow{3}{*}{$\begin{array}{l}0.73 \\
(.482)\end{array}$} \\
\hline & $\geq 5 \&<10$ & $109(66.5)$ & $4.03 \pm 0.38$ & & $3.25 \pm 0.44$ & & $3.27 \pm 0.41$ & \\
\hline & $\geq 10$ & 29 (17.7) & $3.97 \pm 0.35$ & & $3.14 \pm 0.32$ & & $3.33 \pm 0.37$ & \\
\hline \multirow[t]{3}{*}{ Size of facility (person) } & $\leq 50$ & $98(59.8)$ & $3.98 \pm 0.36$ & \multirow{3}{*}{$\begin{array}{l}1.22 \\
(.298)\end{array}$} & $3.27 \pm 0.40$ & \multirow{3}{*}{$\begin{array}{l}2.08 \\
(.128)\end{array}$} & $3.32 \pm 0.37$ & \multirow{3}{*}{$\begin{array}{l}0.27 \\
(.762)\end{array}$} \\
\hline & $>50 \& \leq 100$ & $43(26.2)$ & $4.08 \pm 0.37$ & & $3.26 \pm 0.47$ & & $3.27 \pm 0.43$ & \\
\hline & $>100$ & $23(14.0)$ & $3.98 \pm 0.40$ & & $3.08 \pm 0.34$ & & $3.27 \pm 0.43$ & \\
\hline \multirow{4}{*}{$\begin{array}{l}\text { Sources of information } \\
\text { on infection }\end{array}$} & Continuing education & $71(43.3)$ & $4.02 \pm 0.38$ & \multirow{4}{*}{$\begin{array}{l}0.18 \\
(.910)\end{array}$} & $3.29 \pm 0.40$ & \multirow{4}{*}{$\begin{array}{l}3.05 \\
(.030)\end{array}$} & $3.36 \pm 0.37$ & \multirow{4}{*}{$\begin{array}{l}2.91 \\
(.036)\end{array}$} \\
\hline & Infection prevention guidelines & $43(26.2)$ & $4.00 \pm 0.33$ & & $3.31 \pm 0.42$ & & $3.34 \pm 0.37$ & \\
\hline & Internet & $36(22.0)$ & $4.00 \pm 0.40$ & & $3.13 \pm 0.41$ & & $3.20 \pm 0.44$ & \\
\hline & Others & $14(8.5)$ & $3.95 \pm 0.32$ & & $3.03 \pm 0.34$ & & $3.10 \pm 0.36$ & \\
\hline Experience of education & No & $39(23.8)$ & $4.03 \pm 0.34$ & 0.38 & $3.07 \pm 0.42$ & 3.11 & $3.13 \pm 0.44$ & 3.19 \\
\hline (infection prevention) & Yes & $125(76.2)$ & $4.00 \pm 0.37$ & $(.703)$ & $3.29 \pm 0.39$ & $(.002)$ & $3.35 \pm 0.36$ & $(.002)$ \\
\hline Requirements for & Regular education & $26(15.8)$ & $4.04 \pm 0.39$ & 1.62 & $3.23 \pm 0.43$ & 0.75 & $3.23 \pm 0.36$ & 0.67 \\
\hline infection prevention & Resident nurse & $11(6.7)$ & $3.76 \pm 0.22$ & $(.171)$ & $3.20 \pm 0.33$ & $(.563)$ & $3.21 \pm 0.50$ & $(.612)$ \\
\hline & $\begin{array}{l}\text { Improvement of awareness of } \\
\text { infection prevention by } \\
\text { teachers and parents }\end{array}$ & $102(62.2)$ & $4.03 \pm 0.37$ & & $3.26 \pm 0.41$ & & $3.30 \pm 0.38$ & \\
\hline & Regular visit training & $8(4.9)$ & $3.89 \pm 0.13$ & & $3.01 \pm 0.34$ & & $3.41 \pm 0.34$ & \\
\hline & Others & $17(10.4)$ & $4.02 \pm 0.40$ & & $3.26 \pm 0.46$ & & $3.38 \pm 0.49$ & \\
\hline
\end{tabular}

*Missing data were not included; PPID, practices of preventing infectious diseases.

Table 2. Correlations among Study Variables $(N=164)$

\begin{tabular}{lccc}
\hline Variables & Communication skills & Self-efficacy & $\begin{array}{c}\text { Practices of preventing } \\
\text { infectious diseases }\end{array}$ \\
\cline { 2 - 3 } Communication skills & $\mathrm{r}(p)$ & $\mathrm{r}(p)$ & $\mathrm{r}(p)$ \\
Self-efficacy & 1 & 1 & $.65(<.001)$ \\
Practices of preventing infectious diseases & $.27(<.001)$ & 1 \\
\hline
\end{tabular}

The independent variable of communication skills had a significant effect on the parameter of self-efficacy $(\beta=.27, p<$ $.001)$ and the dependent variable of practices of preventing infectious diseases $(\beta=.19, p=.002)$. In addition, after the mediating variable (self-efficacy), the independent variable (communication skills) had a significant effect on the dependent variable (practices of preventing infectious diseases), which confirmed that self-efficacy support had a partial mediating role (Table 3).

Since the lower and upper coefficients of the 95\% confidence interval did not contain 0 , the mediating effect of selfefficacy was statistically significant (Table 3, Figure 1 ). 
Table 3. Mediating Effect of Self-efficacy in the Relationship between Communication Skills and Practices of Preventing Infectious Diseases $(N=164)$

\begin{tabular}{|c|c|c|c|c|c|c|}
\hline Variables & B & $\beta$ & $\mathrm{t}(p)$ & $\mathrm{R}^{2}$ & Adj. $R^{2}$ & $\mathrm{~F}(p)$ \\
\hline Communication skills $\rightarrow$ self-efficacy & 0.31 & .27 & $3.59(<.001)$ & .074 & .068 & $12.89(<.001)$ \\
\hline Communication skills $\rightarrow$ PPID & 0.38 & .35 & $4.82(<.001)$ & .125 & .120 & $23.24(<.001)$ \\
\hline $\begin{array}{l}\text { Communication skills, self-efficacy } \rightarrow \text { PPID } \\
\text { Communication skills } \rightarrow \text { PPID } \\
\text { Self-efficacy } \rightarrow \text { PPID }\end{array}$ & $\begin{array}{l}0.21 \\
0.56\end{array}$ & $\begin{array}{l}.19 \\
.59\end{array}$ & $\begin{array}{l}3.19(.002) \\
9.75(<.001)\end{array}$ & .450 & .443 & $65.93(<.001)$ \\
\hline
\end{tabular}

CI, confidence interval; PPID, practices of preventing infectious diseases.

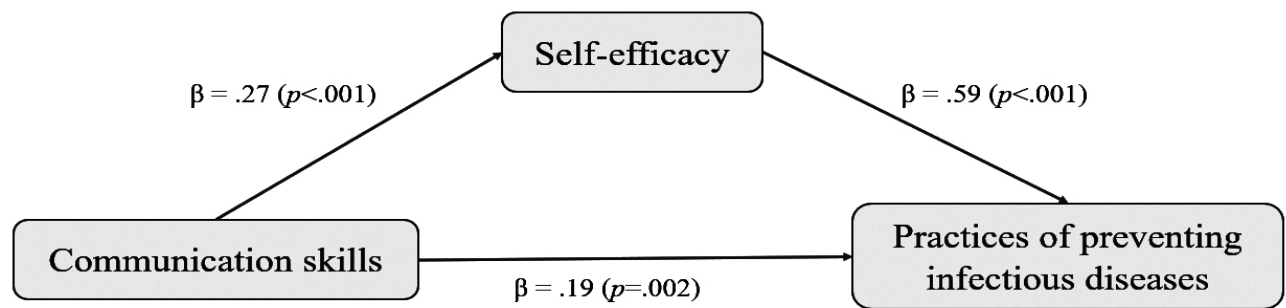

Figure 1. Mediating effect of self-efficacy between communication skills and practices of preventing infectious diseases. The significance of mediation: Boot coefficient=0.17 \pm 0.06 (95\% confidence interval=0.07-0.29).

\section{DISCUSSION}

As the COVID-19 pandemic continues, societal interest in effective infectious disease prevention at daycare centers is increasing [10]. This study was conducted to investigate daycare center teachers' communication skills, self-efficacy, and practices of preventing infectious diseases, and to identify factors that affected the practices of preventing infectious diseases.

Daycare center teachers are in charge of managing infectious diseases as part of their responsibility for the health of infants and toddlers at childcare facilities $[8,11]$. In this study, daycare teachers' sources of information on infection, experiences of education, and perceived requirements for infection prevention were identified. Continuing education was the most common source of information $(43.3 \%)$. However, continuing education is not conducted annually on a regular basis for all teachers [26]. Of the total of 80 hours of education, the allocation of 3 hours to education on infection is very inadequate [26]. Based on these findings, continuing education should be regularly provided to daycare center teachers every year, or steps should be taken to expand the sources of information from which they can acquire knowledge about infection. In this study, $76.2 \%$ of teachers had received education on infection prevention. Teachers who had received education on infection prevention showed statistically significantly higher self-efficacy in preventing infectious diseases and practicing infectious disease prevention than teachers who had not received education on this topic. In the study of Back and Kim [13], daycare center teachers' knowledge of infectious diseases was low, and the demand for education was high. In the study of Yang and Kwon [19], daycare teachers' knowledge of infectious diseases was found to be an important factor related to practices of preventing infectious diseases. As revealed in previous studies $[11,14]$ and in the results of this study, infectious disease prevention education programs for daycare teachers must be developed and implemented for the effective prevention and management of infectious diseases. In addition, when developing an infectious disease prevention education program, customized education reflecting the needs of daycare teachers is required, not uniform education.

This study found that the communication skills of daycare center teachers had a significant effect on self-efficacy and practices of preventing infectious diseases. The government provides childcare center teachers with guidelines for each 
stage of the spread of infectious diseases to lead a stable response to infectious diseases [11,26,27]. Since 2006, when transmission of an infectious disease occurs in a childcare facility, the situation has been entered into an integrated information system $[7,11]$. Daycare teachers play an important role in maintaining and promoting the health of infants and young children through effective communication skills $[11,13]$. In the study of Melnick and Darling-Hammond [28], emphasis was placed on promoting cooperation between daycare center teachers and parents. This study emphasized the need to create an environment in which teachers and institutions can properly recognize the importance of communication and can actively communicate with parents [27]. Parents had a high degree of dependence on daycare teachers in obtaining information about child rearing [27]. Recently, unverified folk remedies and prevention methods have been being delivered to parents through internet portal sites or mom cafes. Therefore, daycare center teachers must deliver accurate medical information regarding the prevention of infectious diseases $[11,14,26]$. This study is significant in that it confirmed the relationship between communication skills and practices of preventing infectious diseases.

In this study, significant positive correlations were found between the communication skills of daycare teachers, self-efficacy in preventing infectious diseases, and practices of preventing infectious disease. In addition, there was a significant positive correlation between teachers' communication skills and practices of preventing infectious diseases. These results are consistent with previous studies showing that a sense of self-efficacy in preventing infectious diseases helps to foster practices of preventing infectious diseases [19,27]. Previous research has mainly focused on knowledge, confidence in practice, and educational needs with an impact on infectious disease prevention practices $[19,20,27]$. However, in the event of an infectious disease such as COVID-19, in order to prevent infectious diseases, the importance of daycare teachers having an understanding of the governmental response guidelines for infectious diseases and close communication with parents is emphasized $[11,26]$ Recently, Seoul has implemented a daycare center visiting nurse system to foster effective communication skills among daycare teachers and to respond appropriately to prevent infectious diseases [29]. In the study of You and $\mathrm{Ju}$ [30], daycare center teachers complained of the burden of children's health management and yearned for new health management methods. As an alternative to this, they wanted the daycare center to become a healthier childcare environment through the visiting nurse system. It is suggested that visiting nurses should provide knowledge about infectious diseases to teachers and parents.

Existing studies have mainly focused on the knowledge, self-efficacy, educational needs, role recognition, and other factors that affect infectious disease prevention practices among daycare teachers and the relationships between them [18-20]. However, in this study, there was a partial mediating effect of self-efficacy for preventing infectious diseases in the relationship between communication skills and practices of preventing infectious disease. These results are similar to earlier findings that self-efficacy influences infectious disease prevention practices [19]. The results of this study on the mediating effect of self-efficacy indicate that efforts are needed to improve both communication skills and practices of preventing infectious diseases. Above all, in this study, the self-efficacy of daycare center teachers had a partial mediating effect on practices of preventing infectious diseases. In order to understand the effect of communication skills on the practices of preventing infectious diseases, it is necessary to explore other mediating factors than self-efficacy.

The limitations of this study are as follows. First, it was conducted among female teachers who worked at five daycare centers in A city, $\mathrm{K}$ city, and S city that were identified through convenience sampling, and there are restrictions on generalization. Second, this study focused on confirming the mediating effect of self-efficacy on the relationship between the communication ability of daycare center teachers practices of preventing infectious diseases, and did not analyze the relationship between the general characteristics of participants and major variables. Despite these limitations, this study obtained basic data and evidence on practices of preventing infectious diseases by investigating daycare teachers' communication skills and self-efficacy for infectious diseases prevention. This study is meaningful in that it presents a strategy for practices of preventing infectious diseases by confirming the mediating effect of self-efficacy in the relationship between communication skills and practices of preventing infectious disease.

\section{CONCLUSION}

This study was conducted to identify the factors that influence childcare teachers' practices of preventing infectious diseases. Previous experiences of infection education showed a significant relationship with self-efficacy and practices of infectious disease prevention. The communication skills of childcare teachers had an effect on their practices of preventing infectious diseases, and self-efficacy for preventing infectious diseases played a mediating role. Based on the results of this study, the following suggestions are made. First, it is necessary to develop an environment and an intervention program for daycare center teachers to receive regular and systematic infection education. Second, it is necessary to provide customized education that reflects daycare center teach- 
ers' levels of existing education and needs. Third, it is necessary to identify effective communication skills for practices of preventing infectious diseases between daycare center teachers and parents. Fourth, it is necessary to develop an intervention program that improves communication skills and self-efficacy for preventing infectious diseases in order to increase practices of preventing infectious diseases by daycare teachers. Fifth, in the COVID-19 pandemic situation, it is necessary to establish a support system in which professional medical personnel can effectively prevent and manage infectious diseases through regular visits to daycare centers by visiting nurses.

\section{Conflict of interest}

No existing or potential conflict of interest relevant to this article was reported.

\section{Data availability}

Please contact the corresponding author for data availability.

\section{REFERENCES}

1. Heo E, Chae Y. Nursery school staff recognition of the policy and consignment system to convert private daycare centers. Journal of the Korea Contents Association. 2020;11 (3):797-812. https://doi.org/10.22143/HSS21.11.3.57

2. Eun KS. Korean women's labor force participation and career discontinuity. Korea Journal of Population Studies. 2018;41(2):117- 150. https://doi.org/10.31693/KJPS.2018.06.41.2.117

3. Song JE, Ahn JA, Lee SK, Roh EH. Factors related to low birth rate among married women in Korea. PLoS one. 2018;13(3):e0194597. https://doi.org/10.1371/journal.pone.0194597

4. Kim US, Kim IT. A study on the problems and improvements of free infant care policy. Industry Promotion Research. 2020;5(2):59-69. https://doi.org/10.21186/IPR.2020.5.2.059

5. Ministry of Health and Welfare. Current status of the number of childcare and children in 2016-2019 [Internet]. Sejong: Ministry of Health and Welfare; 2020 [Cited 2020 November 30]. Available from:

http://index.go.kr/potal/stts/idxMain/selectPoSttsIdxMainPrint .do?idx_cd=1583\&board_cd=INDX_001

6. Limtrakul D, Ongprasert K, Ayood P, Sapbamrer R, Siviroj P. A comparison of child development, growth and illness in homecare and day-care center settings. Journal of Health Research. 2020;34(6):523-534. https://doi.org/10.1108/JHR-08-2019-0193

7. Chung HJ. Issues on the policy of expanding national childcare centers to reinforce the public interest of childcare. Korea Journal of Child Care and Education. 2018;0(113):229-251.

https://doi.org/10.37918/kce.2018.11.113.229

8. Ulset VS, Czajkowski NO, Kraft B, Kraft P, Wikenius E, Kleppestø $\mathrm{TH}$, et al. Are unpopular children more likely to get sick? Longitudinal links between popularity and infectious diseases in early childhood. PloS One. 2019;14(9):1-14.

https://doi.org/10.1371/journal.pone.0222222

9. Vissing NH, Chawes BL, Rasmussen MA, Bisgaard H. Epidemiology and risk factors of infection in early childhood. Pediatrics. 2018; 141(6):e20170933. https://doi.org/10.1542/peds.2017-0933

10. Korea Disease Control and Prevention Agency. Coronavirus Disease-19 [Internet]. Sejong: Ministry of Health and Welfare; 2020 [Cited 2020 December 24]. Available from:

http://ncov.mohw.go.kr/

11. Choi YK. Corona 19 response system diagnosis and tasks of kindergarten and daycare center. Korean Institute of Child Care and Education. 2020;65:6-19.

12. LAWnB. Early childhood care law [Internet]. Seoul: LAWnB; 2020 [cited 2021 January 13]. Available from:

http://www.lawnb.com/lawinfo/contents_view.asp?cid=C39B5 D1A899A49FC8C5D08904AD3ADF2 |0|K

13. Back SH, Kim JS. Child daycare teachers' role perception, knowledge, self-confidence and educational needs regarding infectious disease management in children. Journal of the Korea Contents Association. 2017;17(7):253-264.

https://doi.org/10.5392/JKCA.2017.17.07.253

14. Choi Y. A study on the emotional experiences of child care teachers and changes in their daily routine in centers after COVID-19. Korean Journal of Early Childhood Education Research. 2020;22 (1):253-279. https://doi.org/10.15409/riece.2020.22.1.12

15. Kim YJ, Park JH, Ahn SH. The effects of early child care teachers' communication competence, interpersonal competence and teacher self-efficacy to enlist parental involvement on parent-teacher partnerships. Korean Journal of Child Studies. 2012;33(5):71-89. https://doi.org/10.5723/KJCS.2012.33.5.71

16. Jeong HY, Kim MK. Correlation between communication ability and problem solving ability of daycare center teachers. Journal of Thinking Development. 2018;14(1):121-139.

17. Bandura A. Self-efficacy. In: Ramachaudran VS, editor. Encyclopedia of human behavior. Academic Press; 1994. p. 1534-4536.

18. Kim IO, Park HJ. A survey on the situation, experience and educational need of infectious diseases management of childcare teacher. Korean Journal of Child Education and Care. 2014;14(1):23-50.

19. Yang YJ, Kwon IS. The effects of childcare teachers' infection prevention knowledge, self-efficacy, and emotional labor on their infection prevention practice. Korean Journal of Child Education and Care. 2016;16(1):79-97. https://doi.org/10.21213/kjcec.2016.16.1.79

20. Baek SA, Song SM, Lee YH. Study on influence of communication ability and early childhood teachers' sense of efficacy on organ- 
izational effectiveness of child care centers. Journal of Community Living Science. 2017;28(3):447-460.

https://doi.org/10.7856/kjcls.2017.28.3.447

21. Craig-Unkefer LA, Kaiser AP. Improving the social communication skills of at-risk preschool children in a play context. Topics in Early Childhood Special Education. 2002;22(1):3-13. https://doi.org/10.1177/027112140202200101

22. Heo KH. Construction and validation of a global interpersonal communication competence scale. Korean Journal of Journalism and Communication Studies. 2003;47(6):380-408.

23. Baron RM, Kenny DA. The moderator-mediator variable distinction in social psychological research: Conceptual, strategic, and statistical considerations. Journal of Personality and Social Psychology. 1986;51(6):1173-1182. https://doi.org/10.1037//0022-3514.51.6.1173

24. Hayes AF. Introduction to mediation, moderation, and conditional process analysis: A regression-based approach. New York: The Guilford Press; 2013.

25. Tabachnick BG, Fidell LS. Using multivariate statistics. 4th ed. Boston: Allyn and Bacon; 2000. p. 67-73.

26. Chung HC. Issues and suggestions on operating refresher education for the general duties of childcare center directors. Korea
Journal of Child Care and Education. 2020;124:169-202.

https://doi.org/10.37918/kce.2020.09.124.169

27. Baek SA, Song SM, Lee YH. Study on influence of communication ability and early childhood teachers' sense of efficacy on organizational effectiveness of child care centers. Korean Journal of Community Living Science. 2017;28(3):447-460.

https://doi.org/10.7856/kjcls.2017.28.3.447

28. Melnick H, Darling-Hammond L, Leung M, Yun C, Schachner A, Plasencla S, et al. Reopening schools in the context of COVID-19: Health and safety guidelines from other countries [Internet]. Palo Alto, CA: Learning Policy Institute; 2020 [cited 2021 January 13]. Available from:

https://learningpolicyinstitute.org/product/reopening-schoolscovid-19-brief

29. Seoul Information Communication Plaza. Seoul Metropolitan City doubled the facilities for visiting nurses at daycare centers in Seoul [Internet]. Seoul: Seoul Metropolitan Government; 2020 [Cited 2020 December 6]. Available from: https://opengov.seoul.go.kr/disclosure-of-information/ko/

30. You SY, Joo EK. Perceptions and experiences of childcare teachers for visiting nursing. Korean Society for Wellness. 2020;15(4):181-191. https://doi.org/10.21097/ksw.2020.11.15.4.181 